\title{
UNIVERSIDADE ABERTA E SUA APLICABILIDADE NA ENFERMAGEM *
}

\author{
Sofia Maria Taffil Bello Valente ** \\ Clarinda Takito*** \\ Maria Madalena Januário Leite **** \\ Regina Cavalcanti de Albuquerque Lemmi***** \\ Regina Vitoria Lotti Serrano Abbud ******
}

VALENTE, S. M. T. B.; TAKITO, C.; LEITE, M. M. J.; LEMMI, R. C. A.; ABBUD, R. V. L. S. Universidade aberta e sua aplicabilidade na Enfermagem. Rev. Esc. Enf. USP, São Paulo, 17(3):171-178, 1983.

O trabalho aborda aspectos de um sistema educacional iniciado na Inglaterra, em 1963, denominado Universidade Aberta. Discorre sobre sua estrutura, organizaçāo, avaliação e mostra as tentativas de implantar aquela metodologia no Brasil. As autoras sugerem que a idéia principal da Universidade Aberta - a disseminação do saber - deve ser aproveitada pela enfermagem para encorajar os profissionais a assumirem o compromisso da auto-educaşão e apontam alguns órgãos, por meio dos quais seria possivel divulgar e estender programas a todo pais.

\section{INTRODUÇĀO}

O germe ideológico da UNIVERSIDADE ABERTA nasceu na Inglaterra, em 1963, durante a Campanha Eleitoral Trabalhista ${ }^{8}$, mas somente na gestão do Partido Conservador é que esse tipo de ensino superior foi implantado e seu funcionamento oficial se deu em $1971^{3}$.

A filosofia da UNIVERSIDADE ABERTA baseia-se em dois aspectos importantes. O primeiro, na justiça social, fundamentado no acesso à educação, direito de todo cidadão, enquanto que, no sistema tradicional, o ensino superior é essencialmente para a elite. O segundo atenderia àqueles que deixaram de estudar por falhas do próprio sistema, os que

* Trabalho apresentado à disciplina Problemas do Ensino de Enfermagem, no Curso de Pós-Graduação, nivel de Mestrado da Escola de Enfermagem da USP, 1981.

** Enfermeira. Mestre em Enfermagem. Professor Assistento do Departamento de Enfermagem Médico-Cirúrgica da Escola de Enfermagem da USP - disciplina Entermagem Médico-Cirúrgica.

*** Enfermeira. Auxiliar de Ensino do Departamento de Enfermagem Médico-Cirúrgica da Escola de Enfermagem da USP - disciplinas Introduçăo à Enfermagem $\theta$ Fundamentos de Enfermagem.

**** Enfermeira. Auxiliar de Ensino do Departamento de Orientação Profissional da Escola de Enfermagem da USP - disciplina Administracăo aplicada à Enfermagem.

***** Enfermelra. Professora da Escola de Auxiliares de Enfermagem da Fundaçăo Bradesco, săo Paulo.

****** Enfermeira. 
sofreram as desvantagens do meio ambiente ou os conflitos de após-guerra ou os que pelos próprios erros ou por fatalidade não atingiram seus objetivos ${ }^{12}$.

O critério adotado foi o de aceitar alunos com idade superior a vinte e um anos, porque os com idade inferior ingressavam em Universidades Convencionais. A "Universidade da Segunda Chance" 8 não exige qualificações formais ou acadêmicas prévias para a admissão de alunos ${ }^{12}$ e assume a responsabilidade e o encargo de procurar um meio de ensinar à distância; os estudos são pagos como nas universidades convencionais ${ }^{\circ}$. $O$ instrumento básico é a palavra escrita. $O$ material consiste em livros-texto enviados pelo correio e suplementados com programas de rádio e televisão. $O$ controle é feito através de tutores escolhidos pela própria Universidade e cada um trabalha numa determinada área, acompanhando os alunos da mesma, dando aulas em intervalos regulares numa localidade determinada. A freqüência a essas aulas é voluntária.

Os alunos devem apresentar um trabalho escrito, enviado à casa do tutor a cada duas ou três semanas. Esses trabalhos são examinados detalhadamente pelo tutor e devolvidos aos alunos com comentários, que visam determinar o seu progresso, como também ajudá-los no aprendizado. As provas escritas são feitas em centro de exames e os resultados constituem o item principal na decisão sobre a concessão ou não do crédito, ao aluno e para a sua qualificação.

O sistema da UNIVERSIDADE ABERTA teve pleno êxito na Inglaterra e houve confirmação de que a realidade geral do ensino estava à altura dos padrões exigidos.

\section{ESTRUTURA E ORGANIZAÇÃO DA UNIVERSIDADE ABERTA}

$\mathrm{Na}$ Inglaterra, a UNIVERSIDADE ABERTA é vinculada diretamente ao Ministério da Educação e não ao Comitê Universitário que congrega todas as outras Universidades. Existe um Chanceler, cujo cargo é honorífico e um Vice-Chanceler que é o verdadeiro executivo. Este equivale ao Reitor das Universidades Brasileiras.

A administração superior, no plano deliberativo, é exercido por dois órgãos colegiados: O Conselho, que se ocupa com a administração geral e finanças e o Senado, constituído de professores, que é o órgão máximo da administração acadêmica, correspondendo ao nosso Conselho Coordenador de Ensino e Pesquisa.

Essa estrutura e organização atendem a duas intenções principais: a utilização dos meios de comunicação de massa no processo de ensino e a extensão de atividades universitárias a toda a Grã-Bretanha.

Na estrutura e organização são considerados três aspectos:

- a organização central, sede da Administração da Universidade, onde se concentra o trabalho do corpo docente, de tempo integral, e se 
desenvolvem as atividades de preparação de cursos, de produção e distribuição do material de ensino por correspondência;

- o sistema de coordenações regionais. O país foi dividido em doze regiōes, cada uma supervisionada por um diretor regional, que é o responsável direto pelo centro de estudo local, por professores ("tutors") e por conselheiros (ou orientadores) dos alunos, que normalmente freqüientam os centros;

- Associação da UNIVERSIDADE ABERTA com a "British Brodcasting Corporation", que se encarrega, mediante convênio, da produção dos programas de rádio e televisão ${ }^{3}$.

Os professores se agrupam, segundo as grandes áreas do conhecimento, que correspondem a departamentos amplos, as "Faculdades" (campo do saber determinado). Até 1972, as Faculdades eram em número de seis: Artes (Letras, História, Filosofia, Música, Literatura e Religião), Matemática, Ciências (Física, Química, Biologia e Geociências), Ciências Sociais, Tecnologia e Estudos Educacionais.

Atenção especial deve ser dada ao papel dos "Course Teams", equipes que montam e desenvolvem todos os Cursos e Disciplinas (são responsáveis pela qualidade do material preparado). O "Course Teams" é composto de, pelo menos, dois professores da área da disciplina, um técnico em rádio e televisão (geralmente da "BBC") e um especialista em tecnologias educacionais. O "Team" tem um moderador ou presidente, sobre quem recai a responsabilidade final de congregar os elementos para a pontual confecção e entrega de materiais e programas. Nenhum trabalho é finalizado sem a concordância de todos os elementos do "Team" 8 .

A UNIVERSIDADE ABERTA procurou combinar a especialização com a formação geral. Todo aluno deve seguir duas disciplinas básicas, ("Foundation Courses"), que constituem uma introdução geral e multidisciplinar às matérias ensinadas.

Para obter o grau universitário, o aluno deverá seguir, com aproveitamento, certo número de disciplinas para conquistar os créditos necessários. Há dois tipos de grau: o grau simples, "Pass Degree", para o qual são exigidos seis disciplinas, e o grau com honras "Honours Degree", que requer oito disciplinas. $O$ grau é denominado Bacharel em Artes ("Bachelor of Arts"), seja qual for a área de conhecimento ${ }^{3}$.

A avaliação é feita durante todo o ano. Os processos de ensino empregados são:

- material de instrução enviado pelo correio;

- aulas ("tutorial classes") e serviços de aconselhamento aos alunos nos centros locais de estudos;

- cursos de verão: uma semana de estudos intensivos em estabelecimentos indicados pela Universidade e conduzida por seus professores ${ }^{3}$. 
A maioria dos professores é de preletores ou professores tradicionais de outras Universidades e escolas isoladas, que dedicam parte de seu tempo aos alunos que necessitam de auxílio especial no desenrolar do programa educacional ${ }^{8,11}$. Os conselheiros dirigem centros de estudos, distribuidos por todo o país (centros de multi-atividades onde estudantes, por iniciativa própria, podem estudar, acompanhar filmes, ouvir programas, criar a sua própria infra-estrutura de vida interrelacionada com os colegas e a Universidade).

\section{AVALIAÇÃO DA APLICAÇÃO DO SISTEMA}

Vantagens:

A UNIVERSIDADE ABERTA pretende: alcançar uma quantidade maior de pessoas, através dos diferentes meios de comunicação, proporcionando ensino mais acessivel; melhorar o nivel geral do ensino (aprimoramento cultural), unindo docentes e técnicos de comunicação que usam metodologia e a tecnologia a serviço do ensino superior; facilitar certos tipos de pesquisa (docentes espalhados pelo país colhem dados e informações jamais conseguidas) e utilizam estojos de equipamento ("Kits") em lugar de grandes laboratórios.

\section{Desvantagens:}

O aluno, muitas vezes, sente-se divorciado do mundo estudantil, o ensino é impessoal e a pouca ou nenhuma representação estudantil nos órgãos que elaboram e planejam cursos, faz com que estes não correspondam às necessidades de participação do aluno no mundo contemporâneo. A UNIVERSIDADE ABERTA limita de certa forma as pesquisas, devido à preocupação dos docentes com a produção de programas, elaboração de livros-texto, assistência a reuniões e seminários. Há preocupação constante em relação à dependência de correios, recrutamento e eficiência de professores.

\section{A UNIVERSIDADE ABERTA NO BRASIL}

A idéia do sistema inglês começou a ser discutida no Brasil, visando atender a crescente demanda de ingresso nas Universidades e a necessidade de levar o ensino às regiōes afastadas do País e às classes menos favorecidas.

Em 1972, Jarbas Passarinho, Ministro da Educação e Cultura, criou uma Comissão para estudar a implantação da UNIVERSIDADE ABERTA no Brasil. O Diretor dos Assuntos Universitários do Ministério de Educação e Cultura, Newton Sucupira, elaborou um relatório, após uma visita à Inglaterra, contendo os resultados dos estudos. Com base nesse relatório foi preparado um Projeto de Lei, em 1973, para a implantação do novo sistema educacional em nosso País. Os objetivos eram: possibilitar o acesso ao ensino universitário aos que não podiam freqüentar 
cursos regulares; oferecer atualização a profissionais em serviço; promover cursos experimentais a professores de $1^{\circ}$ e $2^{\circ}$ graus de regiōes menos desenvolvidas; oferecer cursos de atualização e aperfeiçoamento a profissionais e técnicos das áreas prioritárias. Esse Projeto, um dos programas prioritários do I Plano Setorial de Educação e Cultura, não chegou a ser executado por ser considerado inviável, na ocasião.

Nestes anos, o assunto tem sido estudado e discutido, mas dúvidas, contradições e incertezas foram manifestadas quanto à validade e à forma de implantação dessa modalidade de ensino no Brasil.

O tema foi retomado em 1980 pelo Ministro da Educação, na época Eduardo Portella, que considerou a implantação da UNIVERSIDADE ABERTA no Brasil inoportuna. Ela poderia adquirir um caráter de supletivo para "gente bem", quando se faz necessária uma Universidade que não só transmita conhecimento mas também o produza ?. O Conselho Federal de Educação julgou prematura a implantação desse sistema e perigosa a expedição de diplomas, já que o prioritário é fortalecer o sistema já existente, elevar o nivel de ensino e melhorar os Centros de Pesquisa ${ }^{1}$, para se poder implantar o ensino em questão.

A Universidade de Brasilia, que tem liderado os estudos para a implantação da UNIVERSIDADE ABERTA, nestes últimos anos, adquiriu os direitos de tradução em língua portuguesa de 2.000 textos relativos a 130 cursos, cerca de 1.500 filmes e 1.000 audiocassetes. A proposta é fazer um programa cultural de elevado padrão gráfico, de conteúdo e leitura dirigidos, a ser distribuído pela Rede da Fundação Nacional de Material Escolar, Secretarias de Educação e Bancas de Jornal. Para uma segunda fase propõe oferecer cursos de extensão tais como: Relações Internacionais, Ciência Política, Geociência, Cálculo, Biologia e Artes.

No decorrer do tempo, o sistema mereceu amplos estudos, apresentou alguns aspectos relevantes: estrutura de apoio, extensão territorial, pessoal docente e características do educando brasileiro.

No sistema proposto, os veículos básicos para a aprendizagem são: rádio, televisão e correio, meios que não alcançam pessoas das regiōes mais afastadas do País, cujo poder aquisitivo é menor. Um sistema de comunicação falho traz como consequiência um hiato na aprendizagem. Embora o Brasil tenha uma experiência positiva como o "Projeto Minerva", a ampliação em grau e extensão de conteúdos poderia provocar saturação de programas educativos.

A extensão territorial, que dificulta o acesso de informação pelos meios de comunicação, é um fator a ser considerado para a adoção de um sistema centralizado. Diante das grandes variações existentes em nosso País ${ }^{8}$, torna-se difícil estabelecer um modelo educacional adequado que se relacione ao meio ambiente do educando.

Questiona-se, hoje, nas Universidades tradicionais, a suficiência do corpo docente. Para o preparo do material didático há necessidade 
de um corpo docente qualitativa e quantitativamente disponivel. Diante dessa dificuldade, a alternativa adotada foi a importação do material didático, o que pode levar a choques culturais, argumento expresso pelos próprios docentes da UNIVERSIDADE ABERTA inglesa.

A disponibilidade e motivação do estudante brasileiro para gastos com mensalidades, transportes aos centros de estudo, material didático e falta de tempo, de descanso e de lazer são questões de relevância.

Considerando a falta de mão-de-obra qualificada e a condição de aferta do mercado de trabalho para universitários, o questionamento leva a uma indagação: seria viável utilizar alguns principios da UNIVERSIDADE ABERTA como opção no campo da educação permanente e continuada aos já graduados?

\section{UNIVERSIDADE ABERTA E SUA APLICABILIDADE NA ENFERMAGEM}

Considerando que o ensino de Enfermagem deve ser teórico-prático, não vemos possibilidade de aplicação da sistemática da UNIVERSIDADE ABERTA para Cursos de Graduação em Enfermagem e o presente estudo nos mostra que o sistema da UNIVERSIDADE ABERTA, apenas tem sido utilizado nas áreas de Ciências Humanas, Sociais e Matemática; desconhecemos projetos feitos na área de Ciências da Saúde.

Poderíamos, porém, aproveitar a idéia principal da "Open University" - a disseminação do saber - transportando-a para a educação continua dos profissionais de Enfermagem. Estima-se que atualmente, decorridos cinco ou sete anos da educação formal, metade de nosso conhecimento estará obsoleto ${ }^{5}$. A importância fica ainda mais evidenciada, quando analisamos estudos comprovando a relação existente entre a educação contínua e a qualidade da assistência de enfermagem ${ }^{6}$.

A grande maioria dos enfermeiros não tem acesso à educação contínua, particularmente aqueles que trabalham fora dos serviços públicos e dos grandes centros. Há dificuldade de horário disponivel e da necessidade de deslocamento até uma cidade que ofereça um curso. Contudo, como profissionais, é esperado que eles se responsabilizem pela sua própria educação contínua. Isto só é factivel quando existem oportunidades de ensino.

Em certos locais dos Estados Unidos, a educação contínua é tida como obrigatória ${ }^{10}$. Ela poderia ser introduzida no Brasil, como uma responsabilidade das universidades, associações de classe e instituições empregaticias.

Nossa proposta é a criação e consolidação de um sistema de eđucação permanente de aperfeiçoamento e atualização do pessoal de enfermagem, semelhante ao proposto na UNIVERSIDADE ABERTA.

E importante lembrar que o educando adulto tem caracteristicas peculiares, os quais devem ser levadas em consideração numa programa- 
ção; essas pessaas têm limitação de tempo e de horário, sabem o que querem e o que precisam aprender ${ }^{4}$.

Há semelhança entre a filosofia da UNIVERSIDADE ABERTA e os princípios da educação continuada: a utilização dos horários livres; a liberdade de escolha de assuntos que venham ao encontro do interesse e das necessidades sentidas; o estudo independente em casa, quando for conveniente e de acordo com o ritmo do educando ${ }^{2}$.

O Estado de Wisconsin, USA, implantou um sistema de cursos para profissionais de Enfermagem, residentes longe dos centros de educação, através de telefone "The Education Network in Wisconsin". Disca-se para o centro de informações, solicitando determinado assunto, que é transmitido pelo telefone através de fita cassete. Ao final da exposição há um tempo para que sejam formuladas perguntas, que também são respondidas por telefone.

Sistema semelhante é o "Nursing Dial Access", que envia pelo correio fitas cassete gravadas com aulas ${ }^{10}$. Dessa forma conseguiram estender as oportunidades de educação a zonas distantes.

\section{CONCLUSÃO}

O sistema proposto necessitaria que fossem congregados esforços e recursos existentes no País. Poderia ser liderado pela Associação Brasileira de Enfermagem, com a qual seria possivel estender e divulgar programas através das Seções e Distritos dos diversos Estados. A complementação seria feita através de universidades, instituições empregatícias, associações de classe interessadas na promoção de programas de educação continuada.

A concentração de recursos traria uma série de vantagens, isto é, impedir duplicação de esforços e despesas num mesmo tema, descentralizar as oportunidades de educação continuada, repartir entre os profissionais as conquistas realizadas, possibilitar e disseminar o conhecimento de Enfermagem de maneira organizada e eficaz.

Haveria uma coordenação dos assuntos de acordo com as necessidades sentidas e evidenciadas. Seriam utilizados diversos tipos de material didático: livros, fitas gravadas, "slides", filmes, telefone. Quando houvesse comprovação do aproveitamento, o profissional recebria um certificado.

E imperioso que haja extensão das oportunidades de educação continuada para encorajar os profissionais a assumirem o compromisso da auto-educação, buscando otimizar o desempenho na assistência de Enfermagem. 
VALENTE, S. M. T. B.; TAKITO, C.; LEITE, M. M. J.; LEMMI, R. C. A.; ABBUD; R. V. L. S. Open University and its applicability in Nursing. Rev. Esc. Enf. USP, São Paulo, $17(3): 171-178,1983$.

The article covers aspects of a educational system, called Open University, which began in England in 1963. Its structure, organization and evaluation are presented, as well as some attempts to implement the methodology in Brazil. The authors suggest that the idea behind the Open University - dissemination of knowledge - should be incorporated by nurses, in order to encourage them towards continuing education, and indicate some organizations through which such programs could be known and extended throughout the country.

\section{REFERENCIAS BIBLIOGRAFICAS}

1. CONSELHO Federal diz que universidade aberta não deve ser implantada agora. Folha de S. Paulo, São Paulo, 8 abril, 1979.

2. CUTShalL, P. What's it all about? RNABC News, Vancouver, 6(5):8-10, 1974.

3. ESTRUtURA resguarda sua especialidade. Folha de São Paulo, São Paulo, 25 out. 1974.

4. FERVER, J. C. Organization dilemmas in the changing field of adult education. J. Contin. Educ. Nurs., Thorofare, 6(3):20, 1975.

5. KREKELER, K. Continuing education why? J. Contin. Nurs., Thorofare, 6(2):10-6, Mar./Apr. 1975.

6. LUZINSK, R. Continuing education yes, but how? J. Contin. Educ. Nurs., Thorofare, 6(6) :35-6, Nov./Dec. 1976.

7. Ministro desiste da Open. Folha de S. Paulo, São Paulo, 6 mar. 1979.

8. SENN, R. E. Tecnologias avançadas de educação e ensino superior no Brasil. (Tese apresentada com exigência parcial para obtenção do título de Doutor em Educaçăo - Area de Administração Educacional. PUC).

9. TAMBEm na universidade aberta há seleção e taxas. Folha de S. Paulo, São Paulo, 26 abr. 1974.

10. TAYLOR, C. R. Continuing education for nurses. Nurs. Times, London, 71(4):29-32, Apr. 1975.

11. Um desafio ao conformismo. Jormal do Brasil. Rio de Janeiro, 25 fev. 1973.

12. Univeridide aberta. O Estado de S. Panlo, São Paulo, 28 out. 1979. 